\title{
Home practice in mindfulness-based interventions for psychosis groups: a systematic review and qualitative study
}

\author{
Pamela Jacobsen ${ }^{1 *}$ (D) Twinkle Choksi ${ }^{1}$, Katherine Sawyer ${ }^{1}$, Cassia Maximen ${ }^{2}$, Emma Harding ${ }^{2}$ and \\ Matthew Richardson ${ }^{2}$
}

\begin{abstract}
Background: Regular home practice is considered a core component of mindfulness groups and may be associated with better treatment outcomes. This study aimed to (1) review the existing evidence on how much home practice people do in mindfulness-based interventions for psychosis groups, and (2) explore participants' experiences of the barriers and facilitators to completing home practice in a mindfulness for psychosis group using a qualitative study.

Methods: In study 1, we conducted a systematic review of mindfulness-based interventions for psychosis studies and extracted data on home practice rates. In study 2, we conducted semi-structured interviews with people who had completed a mindfulness for psychosis group $(\mathrm{N}=5)$ as part of their routine community care, specifically focusing on experiences of home practice.

Results: Out of 43 studies included in the systematic review, only 5 reported any data on amount of home practice, and none examined the relationship between completion of home practice and treatment outcomes. In the qualitative study, participants described home practice as being difficult but important. Arising themes were similar to findings from previous (non-psychosis) studies suggesting that generic challenges are common, rather than being specific to psychosis.

Conclusions: We recommend that future mindfulness-based interventions for psychosis studies record data on home practice rates, in order to investigate any association between home practice and treatment outcome. Our qualitative findings suggest home practice can be a valued part of mindfulness for psychosis group, and a normalising approach could be taken when and if participants encounter common challenges.
\end{abstract}

Keywords: Mindfulness, Psychotic disorders, Qualitative research, Treatment outcomes, Systematic review

\section{Background}

Mindfulness-based interventions for psychosis have been shown to have many benefits according to recent metaanalyses, including reducing psychotic and affective symptoms, and reducing risk of hospitalisation $[1,2]$. Like other mindfulness-based interventions, it is typically delivered in

\footnotetext{
*Correspondence: pcj25@bath.ac.uk

${ }^{1}$ Department of Psychology, University of Bath, Bath BA2 7AY, UK

Full list of author information is available at the end of the article
}

a group format, which is experiential in nature, with each session including in-group mindfulness practice followed by teacher-led enquiry. Mindfulness-based interventions for psychosis also includes adaptations to meet the particular needs of people with psychotic experiences, such as reduced length of meditation practices (usually around $10 \mathrm{~min}$ ), and more frequent guidance during practices including explicit reference to working with experiences such as voices and paranoia [3]. Another adaptation is a reduced emphasis on home practice, out of recognition 
that people with psychosis might face additional barriers to practising without the support of a group, and the mindfulness therapist present [4]. This may be due to the particularly distressing nature of their symptoms (e.g. hearing critical and hostile voices [5]), as well as cognitive difficulties such as reduced concentration levels [6].

However, it is not yet known whether a decreased emphasis on home practice might actually be stopping participants from getting the most out of a mindfulness for psychosis group given that mindfulness is conceptualised as a skill which is best acquired with frequent practice [7, 8]. For example, in Mindfulness-Based Stress Reduction (MBSR; [7]) and Mindfulness-Based Cognitive Therapy (MBCT; $[8]$ ) the curriculum includes home practice requirements of around 45 min a day, 6 days a week for the duration of the 8-week group. There is also an important distinction made between 'formal' (e.g. body scan) and 'informal' (e.g. mindfulness of everyday activities) home practice in these programmes. Formal mindfulness practises are seen as vital in helping participants to develop key skills. These include how to deliberately turn towards moment-by-moment experience, bring awareness to habitual patterns of responding, and make skilful choices when deciding how to respond, in order to step out of 'automatic pilot' mode. This formal practice lays the foundation for these skills to be deployed when needed in everyday situations, such as when encountering a stressful event. Kabat-Zinn uses the metaphor of regular formal practice as 'weaving your parachute everyday', so it is ready when you need it [7]. This is supported by empirical data from a study by which found that on days when people completed a formal meditation home practice, they responded with greater mindfulness to daily events, which in turn was associated with better psychological well-being [9].

There is evidence from the MBCT for depression literature that increased completion of weekly home practice is associated with better treatment outcome. Crane et al. [10] analysed home practice diaries for 99 participants in a MBCT trial and found that participants who practised on at least three days a week were almost half as likely to have relapsed at 12-month follow-up, compared to people practising $<3$ days a week. A subsequent metaanalysis of $28 \mathrm{MBCT} / \mathrm{MBSR}$ studies in a range of both clinical and non-clinical samples, also reported a statistically significant association between increased home practice and better treatment outcomes $(r=0.26,95 \% \mathrm{CI}$ 0.19-0.34) [11]. Lloyd et al. [12] further conducted a systematic review into controlled trials of MBCT or MBSR groups, restricting their search to only studies which recorded and reported data on home practice completion. They found seven trials with available data on the association between home practice completion and treatment outcome, with four of those reporting a positive association, and three showing no effect.

Despite some equivocal findings, which are to be expected in a heterogeneous literature, the evidence overall supports the premise that formal home practice is an important part of Mindfulness-Based Interventions. Participants should therefore be encouraged to complete the home practice as set in order to get maximum benefit. However, given the time demands and challenging nature of mindfulness practice, it is perhaps no surprise that participants often struggle to complete home practice. For example, Parsons et al. [11] reported an average of $64 \%$ of home practice completed as set in their metaanalysis of 43 studies. An online survey of people who practised mindfulness regularly $(\mathrm{N}=218)$, found that common barriers to home practice including encountering challenges in the practice (e.g. falling asleep), and feeling reluctant to practice when aversive experiences such as boredom or irritation were present [13]. Despite the importance of home practice, meta-syntheses of multiple in-depth qualitative studies show that participants' experiences of what helped or hindered them in home practice has not yet been investigated in any detail [14, 15]. More data is therefore needed on how to best support people to successfully meet commonly encountered challenges in completing home practice.

In summary, we do not yet know whether home practice completion is associated with better treatment outcome in psychosis, as has been found in depression, and how advice and support with completing home practice can best be tailored for this particular clinical group.

The aims of the 2 sequential studies reported in this paper were therefore:

1. To conduct a systematic review on what is currently known about home practice in mindfulness-based interventions for psychosis groups and any association with treatment outcome

2. To conduct a qualitative study of people's experience of the facilitators and barriers to doing home practice during a mindfulness for psychosis group.

\section{Study 1: Systematic review of home practice in mindfulness-based interventions for psychosis groups \\ Method \\ Review questions}

1. (Primary-quantitative) How much formal home practice do people report doing during participation of a mindfulness for psychosis group? 
2. (Secondary-qualitative) What are the reported facilitators/barriers to formal home practice for people taking part in a mindfulness for psychosis group?

A review protocol was written and pre-registered on the Open Science Framework before the searches were run (https://doi.org/10.17605/osf.io/cgakp; 12th March, 2019).

\section{Searches}

We initially conducted searches for mindfulness-based interventions for psychosis studies in the electronic databases Scopus and PubMed for peer-reviewed journal articles published in English up to 31st December 2018. Additional search terms were added to address the secondary review question, as we anticipated that some relevant data might be published as separate qualitative or mixed-methods papers (see Additional file 1 for complete list of search terms). Initial searches were run between March and June 2019. The systematic review was later updated, with searches being run up to 12th October 2021 (run in October 2021).

\section{Inclusion/exclusion criteria}

For the primary review question any study design was included, so long as empirical data was reported (i.e. excluding commentary or review papers). This included randomized controlled trials, non-randomized controlled trials, and uncontrolled studies. Likewise, for the secondary review question, any study design was included, so long as empirical data was reported, including mixed methods studies and solely qualitative studies. Studies were included if participants were at least 16 years old and were taking part in mindfulness-based interventions for psychosis groups, regardless of diagnosis or symptom profile. Studies were eligible for inclusion if they described and/or evaluated a mindfulness group intervention (of however many sessions or duration of treatment), including at least one formal guided practice per group session with teacher-led inquiry after each practice. Therapies described predominantly as compassion- or acceptance based were not included if they did not meet these criteria.

\section{Study selection and data extraction}

One reviewer first screened all titles and abstracts identified from searches to determine eligibility. At the full-text screening stage, two reviewers independently screened articles for inclusion, with any discrepancies resolved by discussion. Where needed, corresponding authors were contacted to ask for any missing data that could have helped to assess eligibility. Reasons for exclusion at the full-text screening stage were recorded. For included studies, multiple reports from the same study, based on the same underlying data from the same participants, were linked together. We linked studies based on matching trial registration numbers where available, references to linked papers in the reports themselves, and consultation with authors where required. For summary of searches see PRISMA diagrams: Fig. 1 (primary review question) and Fig. 3 (secondary review question; Additional file 1). We used a standardised data extraction template to record relevant information from each included study, with a sample double-checked for consistency.

\section{Quality assessment}

The quality of eligible studies was assessed using the Mixed Methods Appraisal Tool (MMAT; [16]). The MMAT is designed to assess quantitative, qualitative and mixed methods studies using a single integrated tool which also incorporates criteria for assessing RCTs in line with the Cochrane criteria [17]. A summary score is calculated by dividing the number of criteria definitely met (i.e. scored as a 'yes') divided by 4 and expressed as a percentage. Quality scores therefore ranged from 0 to $100 \%$.

\section{Data synthesis}

For the primary quantitative question, we planned to calculate the range and mean average of the proportion of participants who reported doing any formal home practice, and the pooled average of the numbers of minutes per day, or average numbers of sessions of practice per week, over the course of the group. For the secondary qualitative question, we planned to report a narrative synthesis of qualitative data reporting facilitators and barriers to formal home practice.

\section{Results}

Primary review question: how much formal home practice do people report doing during participation of a mindfulness for psychosis group group? (Quantitative) Study characteristics

Table 1 show the characteristics of studies included in the primary review question $(n=43)$. A range of study designs were included: Randomised controlled trials (RCTs; $n=18)$, non-randomised controlled trial $(n=3)$, uncontrolled pre-post studies $(n=19)$, qualitative studies $(n=3)$. In studies that used a comparison group $(n=21)$ these were: Treatment as Usual (TAU, $n=14)$, waitlist $(\mathrm{n}=2)$, active control $(\mathrm{n}=3)$ and both active control + TAU comparison groups $(n=2)$. Quality assessment using the Mixed Methods Appraisal Tool (MMAT) resulted in 4/43 studies being assessed as low quality (scoring $0 \%$ or $25 \%$ ), $14 / 43$ as medium quality (scoring $50 \%$ ) and $25 / 43$ as high quality (scoring $75 \%$ or $100 \%$ ). 


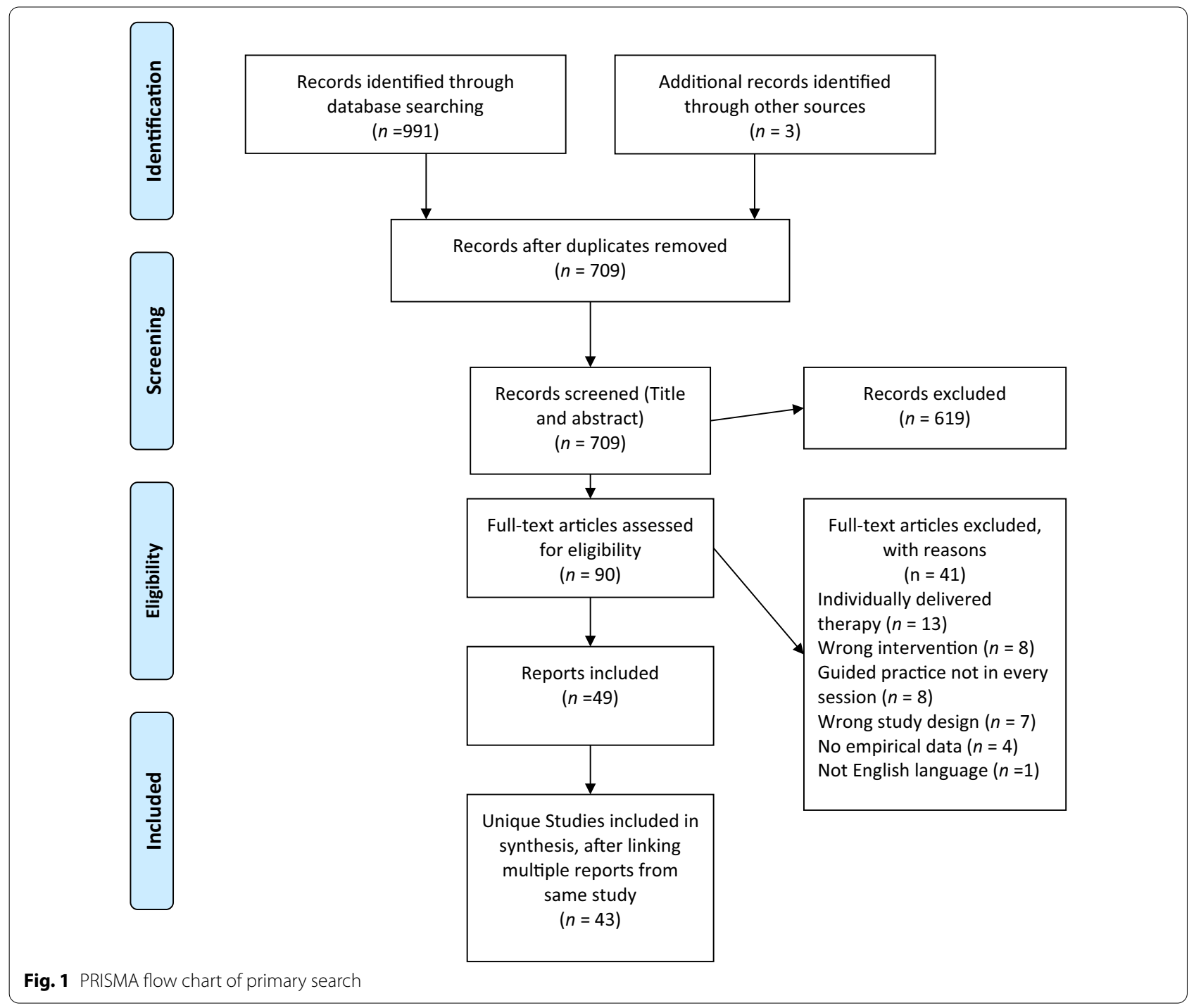

\section{Amount of formal home practice}

Twenty-six out of the 43 studies (60\%) described guidance given for home practice to participants within the treatment protocol (Table 2). Sixteen of these studies $(16 / 26)$ included formal home practice as a core part of the intervention and set home practice assignments, with the remaining 10 studies encouraging home practice but not setting weekly assignments. Resources to help support participants to complete home practice included providing CDs of guided practises, written scripts, handouts, and forms to record home practice. Only five studies reported amount of home practice in a format that allowed for calculation of average numbers of minutes/ day, or days/week [18-22] The frequency which people reported home practice ranged from 3 to 7 days/week, and the average duration of each home practice ranged from 1 to $30 \mathrm{~min}$ (we did not calculate a pooled estimate due to heterogeneity between studies, and the sparse data available). None of these five studies reported any analyses which examined the association between home practice completion and treatment outcome.

\section{Secondary review question: what are the reported facilitators/barriers to formal home practice for people taking in a mindfulness for psychosis group? (Qualitative) Study characteristics}

We extracted qualitative data where available from the $11 / 43$ studies included in the primary research question, categorised as either fully qualitative or mixed methods [18-21, 23-29]. Additional searches for solely qualitative studies resulted in an additional 6 relevant papers being identified (Additional file 1: Fig. S3). These additional qualitative papers, all conducted in the United Kingdom 


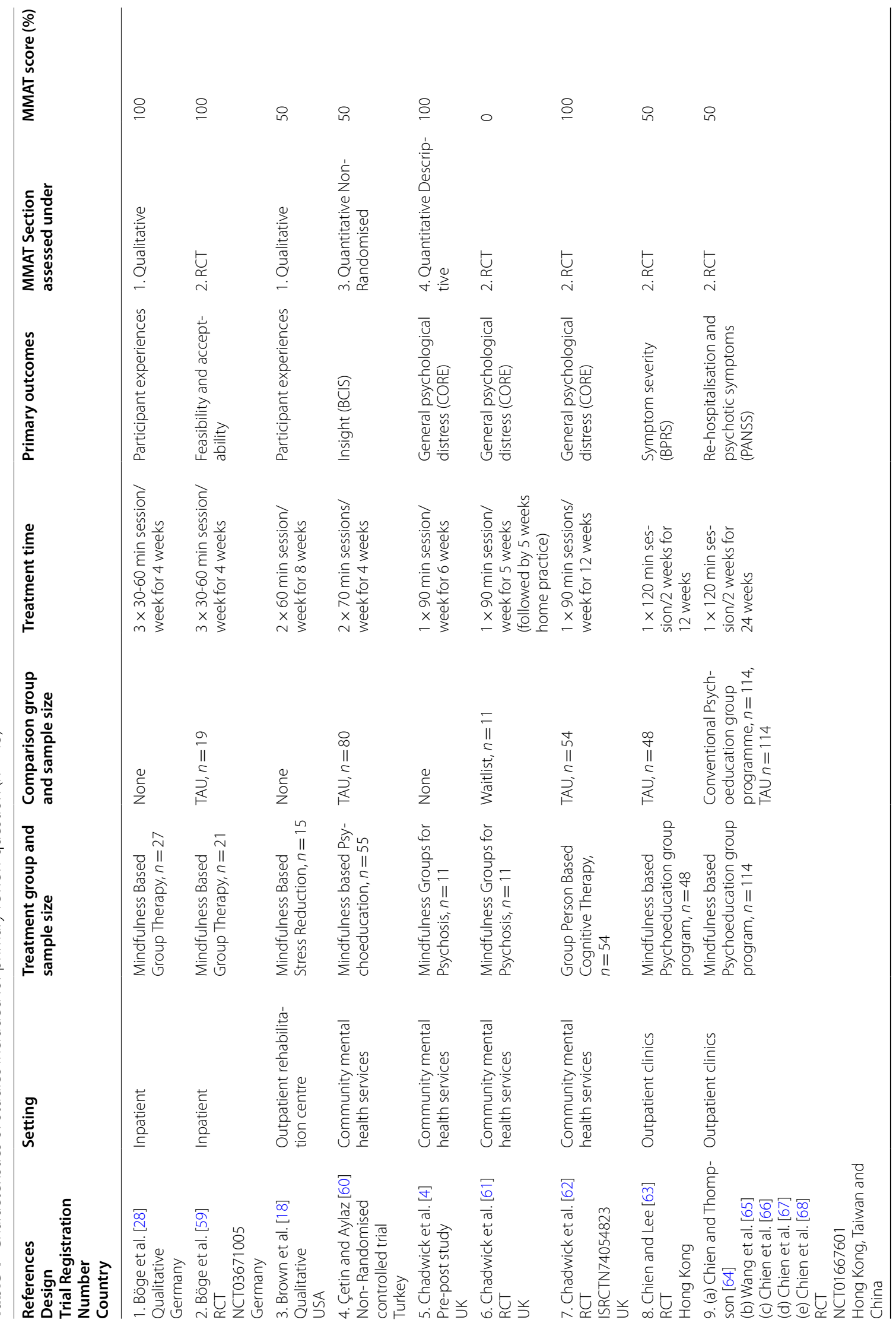




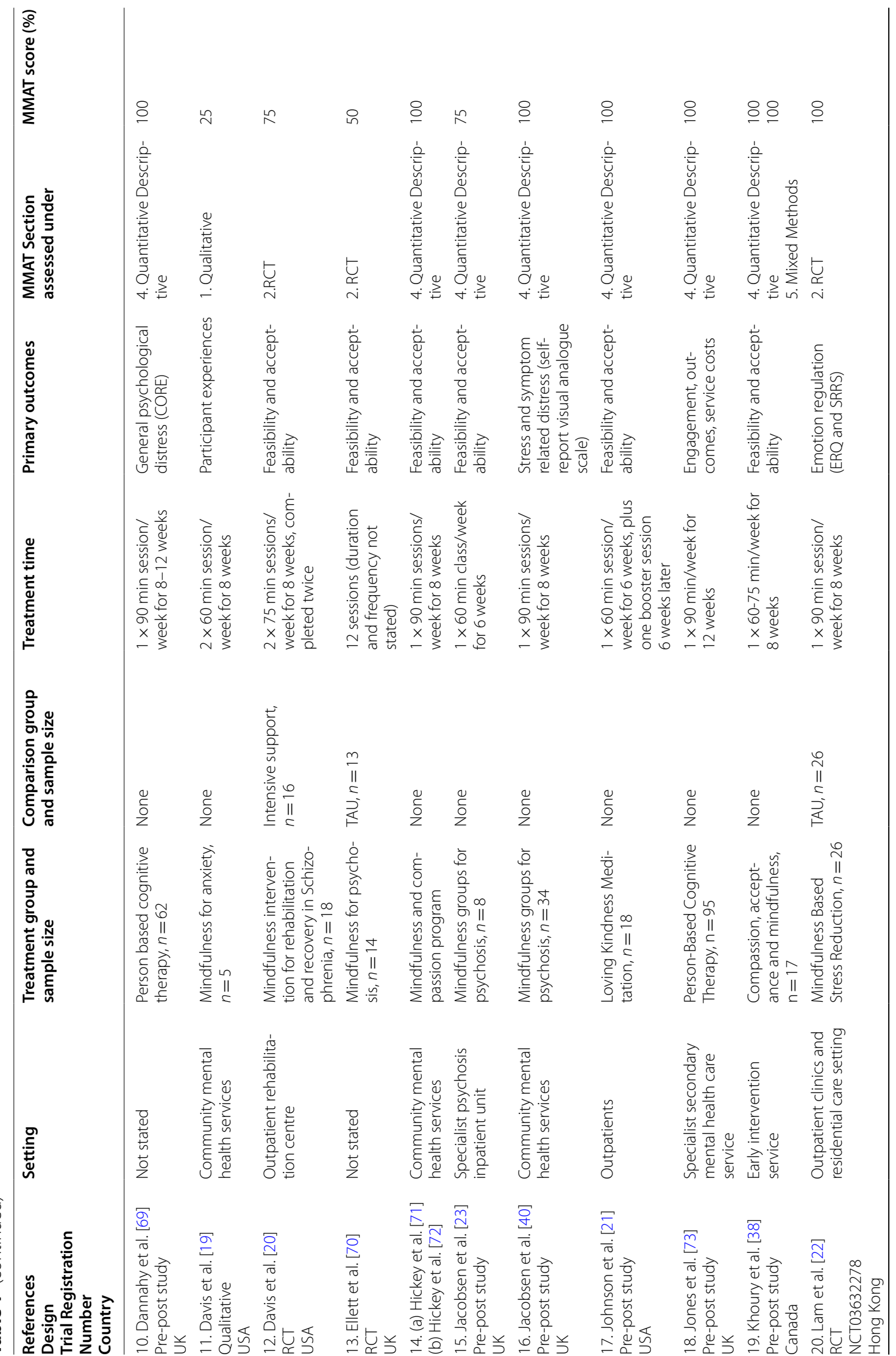




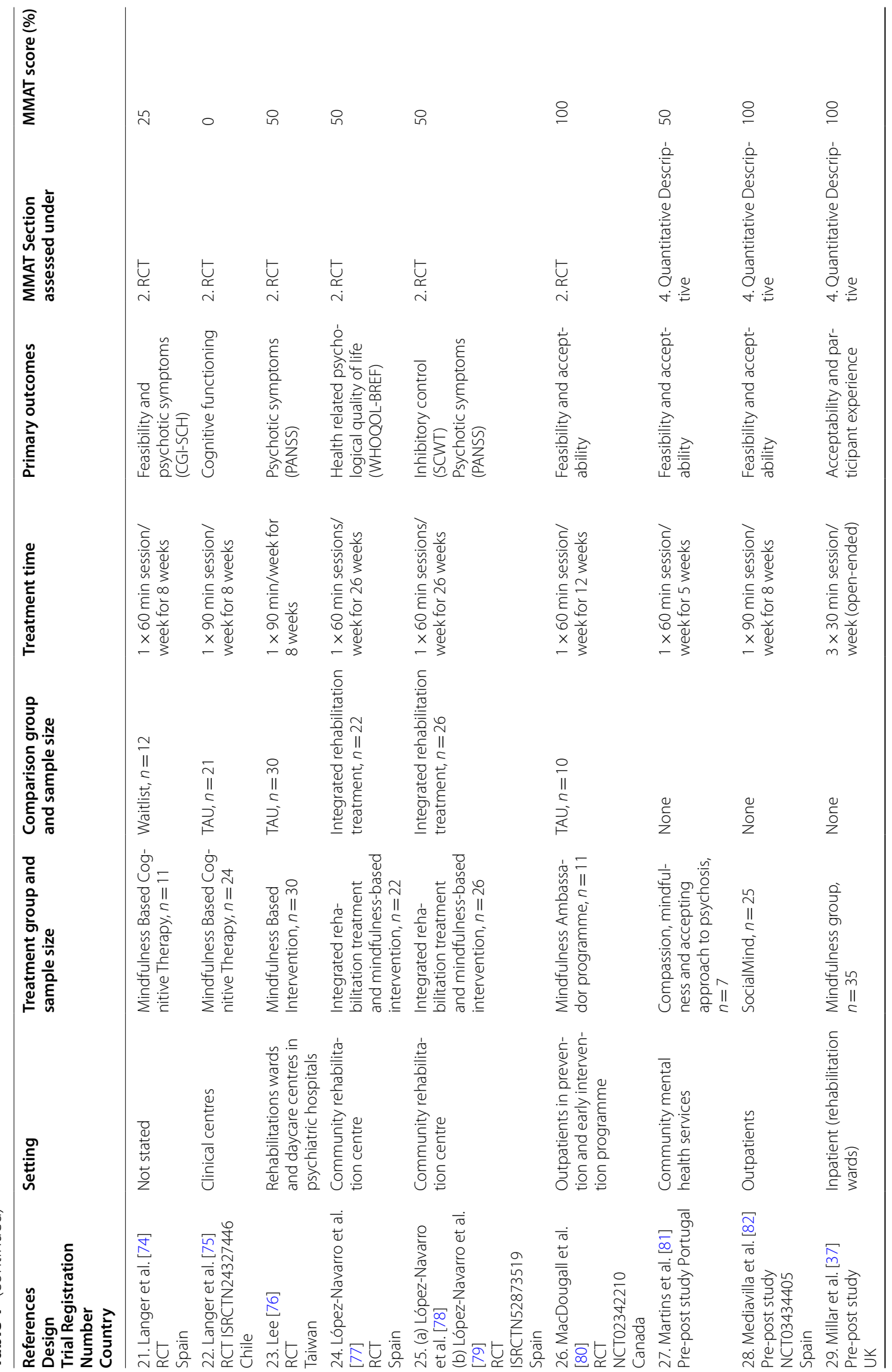




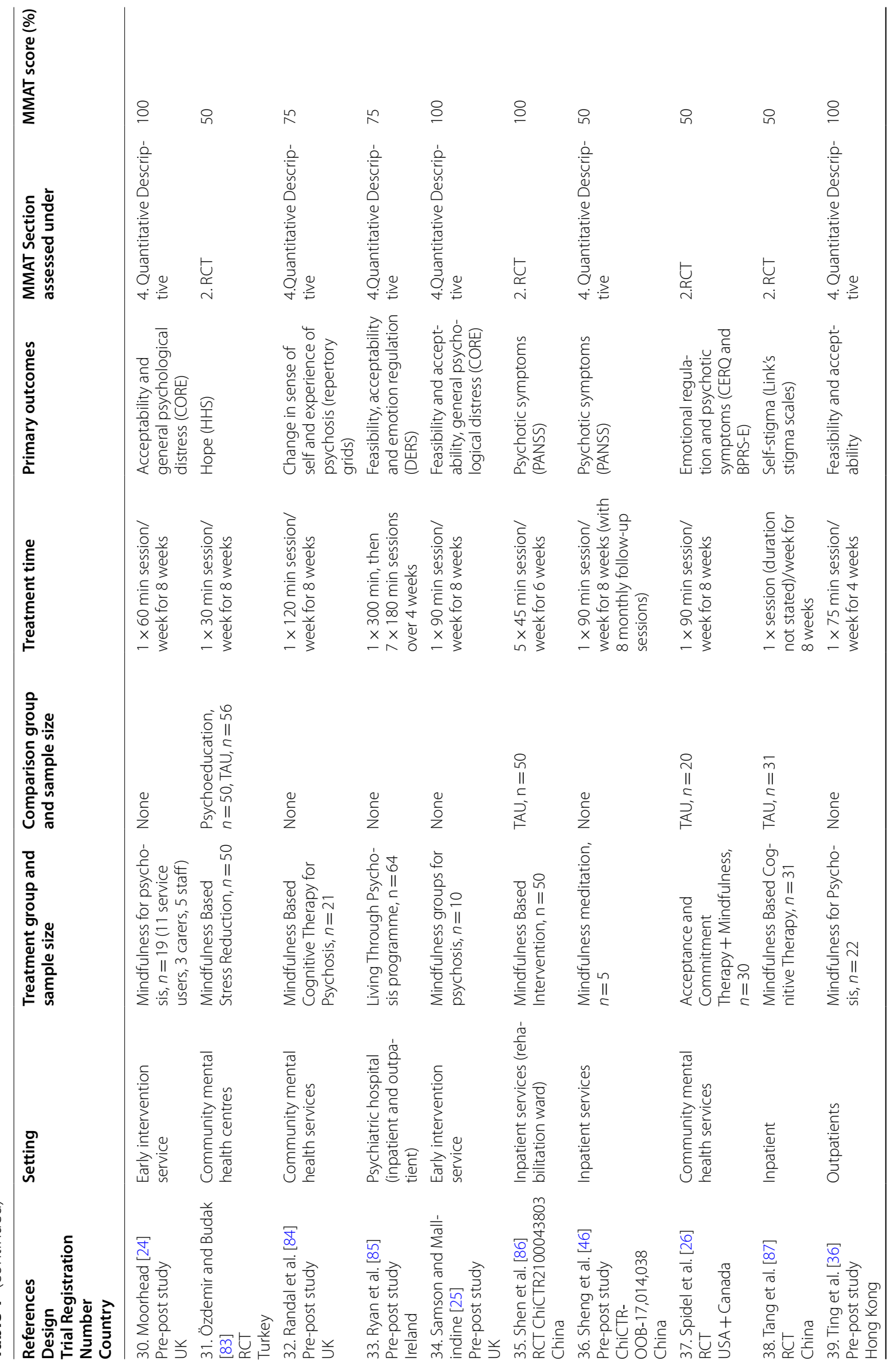




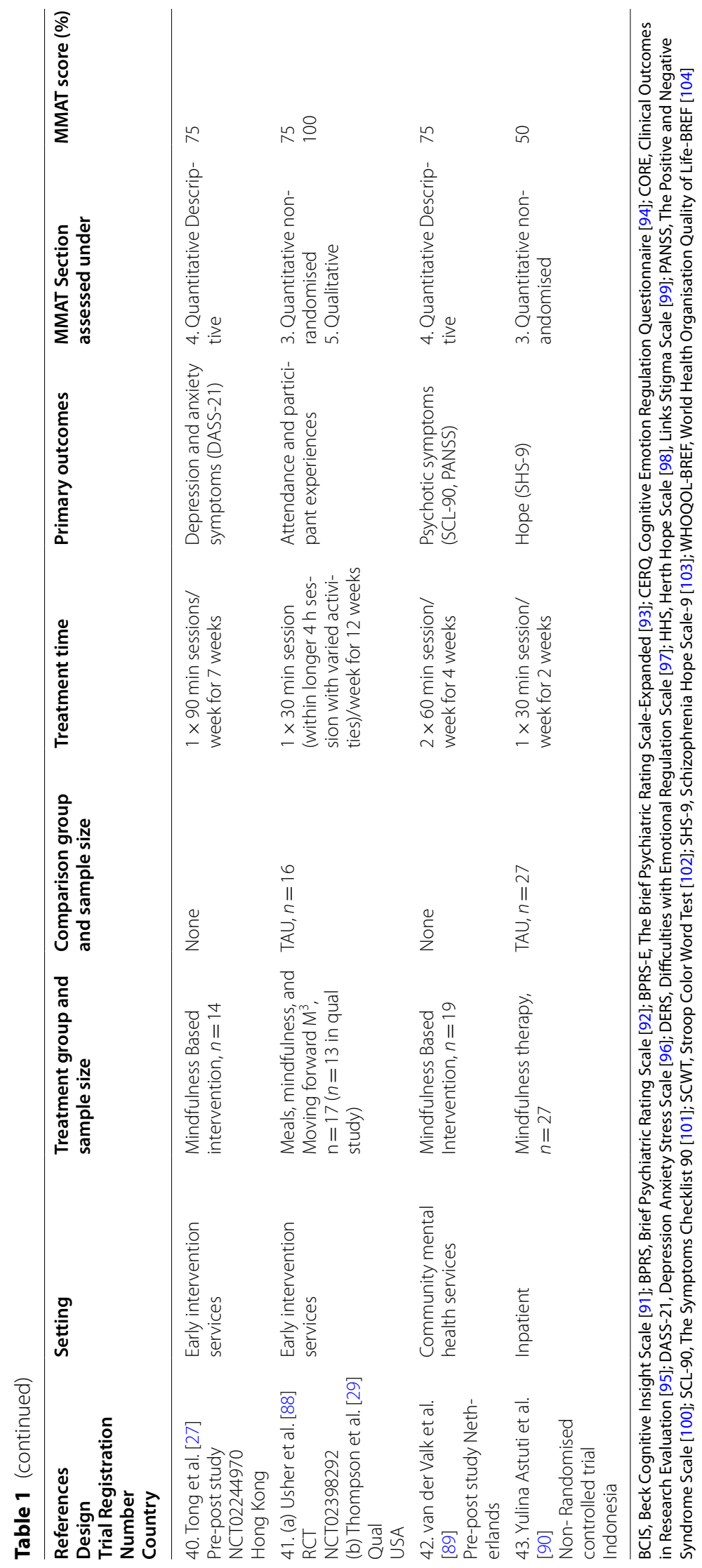


Table 2 Studies which included instructions/guidance on home practice $(n=26)$

\begin{tabular}{|c|c|c|c|c|c|}
\hline References & $\begin{array}{l}\text { Guidance for home } \\
\text { practice }\end{array}$ & $\begin{array}{l}\text { Resources given for } \\
\text { home practice }\end{array}$ & $\begin{array}{l}\text { Is home practice } \\
\text { measured (if so, } \\
\text { how?) }\end{array}$ & $\begin{array}{l}\text { Proportion of } \\
\text { participants who } \\
\text { report any formal } \\
\text { home practice }\end{array}$ & $\begin{array}{l}\text { Average reported } \\
\text { formal home practice } \\
\text { (Practice per day, or } \\
\text { average number of } \\
\text { practices per week) }\end{array}$ \\
\hline 1. Brown et al. [18] & $\begin{array}{l}\text { Home practice core } \\
\text { requirement }\end{array}$ & Guided meditation CDs & Yes (not stated how) & 14/15 participants & $\begin{array}{l}24.71 \mathrm{~min} / \text { day, SD } 18.44 \\
\text { Range }=0.88-64.14\end{array}$ \\
\hline 2. Çetin and Aylaz [60] & $\begin{array}{l}\text { Home practice core } \\
\text { requirement }\end{array}$ & $\begin{array}{l}\text { Guided meditation } \\
\text { CDs and booklet }\end{array}$ & No & Not recorded & N/A \\
\hline 3. Chadwick et al. [4] & $\begin{array}{l}\text { Encouraged but not } \\
\text { required }\end{array}$ & $\begin{array}{l}\text { Guided meditation } \\
\text { audiotapes }\end{array}$ & No & Not recorded & N/A \\
\hline 4. Chadwick et al. [61] & $\begin{array}{l}\text { Encouraged but not } \\
\text { required }\end{array}$ & Guided meditation CDs & No & Not recorded & N/A \\
\hline 5. Chadwick et al. [62] & $\begin{array}{l}\text { Encouraged but not } \\
\text { required }\end{array}$ & Guided meditation CDs & No & Not recorded & N/A \\
\hline 6. Chien and Lee [63] & $\begin{array}{l}\text { Home practice core } \\
\text { requirement }\end{array}$ & Not stated & No & Not recorded & N/A \\
\hline $\begin{array}{l}\text { 7. (a) Chien and } \\
\text { Thompson [64] } \\
\text { (b) Wang et al. [65] } \\
\text { (c) Chien et al. [66] } \\
\text { (d) Chien et al. [67] } \\
\text { (e) Chien et al. [68] }\end{array}$ & $\begin{array}{l}\text { Home practice core } \\
\text { requirement }\end{array}$ & Not stated & No & Not recorded & N/A \\
\hline 8. Davis et al. [19] & $\begin{array}{l}\text { Encouraged but not } \\
\text { required }\end{array}$ & Guided meditation CDs & Yes (self-report) & $5 / 5$ participants & $\begin{array}{l}2 \text { ps reported doing } \\
\text { daily one-minute breath- } \\
\text { ing spaces } 3 \text { ps reported } \\
5-30 \text { min of daily } \\
\text { practice }\end{array}$ \\
\hline 9. Davis et al. [20] & $\begin{array}{l}\text { Home practice core } \\
\text { requirement }\end{array}$ & $\begin{array}{l}\text { Guided meditation CD } \\
\text { and homework forms }\end{array}$ & $\begin{array}{l}\text { Yes (record form } \\
\text { handed in each week) }\end{array}$ & Not stated & $\begin{array}{l}28.72 \text { min on an average } \\
\text { of } 54 \% \text { of days }\end{array}$ \\
\hline 10. Jacobsen et al. [23] & $\begin{array}{l}\text { Encouraged but not } \\
\text { required }\end{array}$ & Guided meditation CDs & No & Not recorded & N/A \\
\hline 11. Johnson et al. [21] & $\begin{array}{l}\text { Home practice core } \\
\text { requirement }\end{array}$ & Guided meditation CDs & Yes (self-report) & Not recorded & $\begin{array}{l}\text { Mean } 3.7 \text { days/week } \\
(S D=1.4) \\
19.1 \text { min per practice } \\
(S D=14.6)\end{array}$ \\
\hline 12. Jones et al. [73] & $\begin{array}{l}\text { Home practice core } \\
\text { requirement }\end{array}$ & Audio recordings & No & Not recorded & N/A \\
\hline 13. Lam et al. [22] & $\begin{array}{l}\text { Home practice core } \\
\text { requirement }\end{array}$ & $\begin{array}{l}\text { Guided meditations on } \\
\text { MP3 players, practice } \\
\text { manual and logbook }\end{array}$ & $\begin{array}{l}\text { Yes (record form } \\
\text { handed in each week) }\end{array}$ & $\begin{array}{l}\text { 14/26 participants } \\
\text { (according to ITT } \\
\text { analysis) }\end{array}$ & $\begin{array}{l}\text { Mean } 31 \text { min per week } \\
\text { ( } \mathrm{SD}=17.34 \text {, range } \\
0-86.4 \text { min per week) }\end{array}$ \\
\hline 14. Langer et al. [74] & $\begin{array}{l}\text { Home practice core } \\
\text { requirement }\end{array}$ & $\begin{array}{l}\text { Guided meditation } \\
\text { CDs and homework } \\
\text { forms }\end{array}$ & No & Not recorded & N/A \\
\hline 15. Lee [76] & $\begin{array}{l}\text { Home practice core } \\
\text { requirement }\end{array}$ & Not stated & No & Not recorded & N/A \\
\hline $\begin{array}{l}\text { 16. López-Navarro et al. } \\
\text { [77] }\end{array}$ & $\begin{array}{l}\text { Encouraged but not } \\
\text { required }\end{array}$ & $\begin{array}{l}\text { Guided meditation } \\
\text { audiotapes }\end{array}$ & No & Not recorded & N/A \\
\hline $\begin{array}{l}\text { 17. (a) López-Navarro } \\
\text { et al. [78] } \\
\text { (b) López-Navarro et al. } \\
\text { [79] }\end{array}$ & $\begin{array}{l}\text { Encouraged but not } \\
\text { required }\end{array}$ & $\begin{array}{l}\text { Guided meditation } \\
\text { audiotapes }\end{array}$ & No & Not recorded & N/A \\
\hline $\begin{array}{l}\text { 18. MacDougall et al. } \\
\text { [80] }\end{array}$ & $\begin{array}{l}\text { Home practice core } \\
\text { requirement }\end{array}$ & Not stated & No & Not recorded & N/A \\
\hline 19. Martin et al. [81] & $\begin{array}{l}\text { Encouraged but not } \\
\text { required }\end{array}$ & $\begin{array}{l}\text { Mindfulness scripts } \\
\text { and hand outs }\end{array}$ & No & Not recorded & N/A \\
\hline 20. Mediavilla et al. [82] & $\begin{array}{l}\text { Home practice core } \\
\text { requirement }\end{array}$ & Audio recordings & No & Not recorded & N/A \\
\hline $\begin{array}{l}\text { 21. Özdemir and Budak } \\
\text { [83] }\end{array}$ & $\begin{array}{l}\text { Home practice core } \\
\text { requirement }\end{array}$ & Booklet & No & Not recorded & N/A \\
\hline
\end{tabular}


Table 2 (continued)

\begin{tabular}{|c|c|c|c|c|c|}
\hline References & $\begin{array}{l}\text { Guidance for home } \\
\text { practice }\end{array}$ & $\begin{array}{l}\text { Resources given for } \\
\text { home practice }\end{array}$ & $\begin{array}{l}\text { Is home practice } \\
\text { measured (if so, } \\
\text { how?) }\end{array}$ & $\begin{array}{l}\text { Proportion of } \\
\text { participants who } \\
\text { report any formal } \\
\text { home practice }\end{array}$ & $\begin{array}{l}\text { Average reported } \\
\text { formal home practice } \\
\text { (Practice per day, or } \\
\text { average number of } \\
\text { practices per week) }\end{array}$ \\
\hline 22. Randal et al. [84] & $\begin{array}{l}\text { Home practice core } \\
\text { requirement }\end{array}$ & $\begin{array}{l}\text { Guided meditation } \\
\text { CDs and hand-outs }\end{array}$ & No & Not recorded & $\mathrm{N} / \mathrm{A}$ \\
\hline 23. Ryan et al. [85] & $\begin{array}{l}\text { Home practice core } \\
\text { requirement }\end{array}$ & $\begin{array}{l}\text { Wallet cards/work- } \\
\text { sheets for skills practice }\end{array}$ & No & Not recorded & $\mathrm{N} / \mathrm{A}$ \\
\hline $\begin{array}{l}\text { 24. Samson and Mall- } \\
\text { indine }[25]\end{array}$ & $\begin{array}{l}\text { Encouraged but not } \\
\text { required }\end{array}$ & Not stated & No & Not recorded & $\mathrm{N} / \mathrm{A}$ \\
\hline 25. Sheng et al. [46] & $\begin{array}{l}\text { Home practice core } \\
\text { requirement }\end{array}$ & Not stated & $\begin{array}{l}\text { Yes (record form } \\
\text { handed in each week) }\end{array}$ & Not stated & $\mathrm{N} / \mathrm{A}$ \\
\hline $\begin{array}{l}\text { 26. Van der Valk et al. } \\
\text { [89] }\end{array}$ & $\begin{array}{l}\text { Encouraged but not } \\
\text { required }\end{array}$ & Guided meditation CDs & No & Not recorded & $\mathrm{N} / \mathrm{A}$ \\
\hline
\end{tabular}

(UK), were conducted across a range of service settings, including an acute inpatient ward [30], an early intervention service [31], and community mental health services [32-35]. Three used grounded theory as the qualitative analytical approach [31, 34, 35], 2 used thematic analysis [30,33], and 1 used interpretative phenomenological analysis (IPA) [32]. A total of 17 studies were therefore included in this qualitative part of the review.

\section{Reported facilitators and barriers}

We began the data synthesis by looking at the 10/17 included studies which were fully qualitative (as opposed to mixed-methods), on the basis that they were likely to yield the richest data. Our first observation was that these studies had primarily focused on participants' experiences of the group itself, and in-session mindfulness practice, and most did not include any specific questions in their interview schedule about home practice. Perhaps unsurprisingly therefore, four studies did not report any qualitative data at all relating to home practice [31-34]. Brown et al. did include a specific question about "barriers" participants might have encountered in completing home practice in their study [18]. Participants mentioned difficulties in fitting their mindfulness practice into their daily schedule, and difficulties in their home environment which made it more difficult to practise e.g. noise and disturbance in shared accommodation. Similar themes were reported by McHale et al. in terms of successful completion of home practice being contingent on the 'right' conditions (e.g. it being easier when feeling relaxed, and when the home environment was quiet vs. feeling agitated, and/or there being noise around at home) [35]. Some participants in an inpatient study spontaneously reported practising between sessions, and intending to carry this on at home after discharge as it had been beneficial for them: "well it's just got me through so much, you know? I'll carry on with it even if it's at home on my own"-([30], pg.606). This was also reported in another inpatient study, within the theme of 'transfer to everyday life ([28], pg.10)': "This exercise was much easier to implement [than Progressive Muscle Relaxation], and that's why I find it much better. I can do it at home alone." This may have been an over-optimistic goal however, as participants in community groups often reported more ambivalence towards completing home practice, for example in saying they struggled to make regular time for it in their schedules [19].

We then moved on to reviewing the data extracted from the remaining mixed-methods studies, to build on our initial synthesis of findings. We found that the majority of mixed-methods studies yielded limited qualitative data from feedback forms or brief interviews, and did not report any findings specifically about home practice $[20,21,23-26,36-38]$. The one exception to this was the study by Tong et al. [27], who conducted a full grounded theory analysis of the experience of 11 group participants. The paper reported 2 relevant themes on home practice; 'Difficult to practice outside of group' and 'Stressful when discussing home practice'. The latter theme was illustrated by the following quote in the paper: "Perhaps I'm too lazy and didn't spend much time at home practicing, so when I'm being asked about the homework, I felt some pressure." (pg. 557). This is interesting as it highlights the potential for home practice to trigger feelings of shame or high levels of self-criticism when participants feel they are failing to complete it. This links back to Chadwick's original stance on home practice in mindfulness for psychosis groups which was that too much emphasis on home practice could be counterproductive in this clinical population due to a greater sensitivity to perceived failure experiences [39]. 
In summary, we found that most mindfulness-based interventions for psychosis studies did mention home practice in their protocols, with over a third (37\%) including home practice as a core requirement and setting regular home practice. However, very few studies measured or reported how much home practice people were doing. It is therefore not currently possible to say how much home practice people do when undertaking a mindfulness for psychosis group, or whether completion of home practice is linked to better treatment outcome. Qualitative data is also lacking on what people's experiences of home practice are, and specifically what might help (facilitate) or hinder them (barriers) to complete home practice. The aim of study 2 was therefore to conduct a qualitative study to fill this gap in our current knowledge.

\section{Study 2: Qualitative study of facilitators and barriers to home practice Method Research question}

What are the self-reported facilitators and barriers to people doing home practice during a mindfulness-based interventions for psychosis group?

\section{Participants and procedure}

Participants were recruited from a Community Mental Health Team (CMHT) in a UK NHS Trust where 8-week mindfulness for psychosis groups were offered to service users as part of routine care (see Jacobsen et al. [40] for a more detailed description of the group intervention). Home practice was encouraged as part of the groups but was not a core requirement. We used purposive sampling [41] as we were interested in selecting participants specifically for the particular characteristic that they had taken part in a mindfulness group at the CMHT. As information on home practice completion was not routinely recorded by the group therapists, it was not possible to sample purposively on the basis of whether people had or had not completed home practice. However, we made it clear that we were interested in talking to people who may or may not have done any home practice during their mindfulness group in order to learn more about a range of experiences. Eligible participants were approached to take part by a member of CMHT staff. Interviews were conducted over the phone, or in person at the CMHT team base, by a graduate research student or assistant psychologist, using a semi-structured interview schedule (see Additional file 1). The assistant psychologist $(\mathrm{CM})$ worked as part of the clinical team at the CMHT, but was not previously known to any of the service users they interviewed, and also had not been involved with running the mindfulness for psychosis groups. The graduate research students (TC \& KS) were not previously known to any of the participants and had never been part of the clinical team at the CMHT. Interviews were audio recorded for transcription, and the interviewers also took contemporaneous paper notes. Two peer experts, with lived experience of mental health difficulties, were involved in developing and reviewing all study materials, including the information sheet, consent form and interview schedule. This was to ensure all information was explained clearly to participants, and interviews were conducted with sensitivity and respect. For example, peer experts emphasised the importance of wording the interview questions sensitively so that participants did not feel they were being judged badly for not completing home practice, or finding it difficult. The study protocol was written and pre-registered on the Open Science Framework before recruitment started (https://doi.org/10.17605/osf.io/cgakp; 22nd May, 2019).

\section{Data analysis}

Data collection and analysis were conducted in parallel. Interviews were transcribed verbatim using Jeffersonian Transcription Notation [42], which includes annotations on transcripts to give extra information about conversational context, such as pauses in speech, or rising/falling pitch or intonation (see Additional file 1 for notation key). The data were analysed using thematic analysis to identify recurring patterns of meaning within the data (themes) and the relationship between the themes [43]. We adopted a critical realist stance, based on the principle that there is no single absolute reality and knowledge is subjective and mediated by individual perceptions and beliefs. We therefore selected thematic analysis as the most appropriate method of analysis as it is theoretically and epistemologically flexible [44]. In line with the study aims, and to stay close to participant's narrative, the analysis derived themes predominantly on a descriptive and semantic level. Initial codes were generated, and then refined using an iterative process through re-reading transcripts and the subset of codes were sorted into themes and sub-themes. Each theme was then reviewed at the coding level by re-reading the data extracts and ensuring they fit into each theme and reviewed at the level of the theme to ensure each theme coherently links to other themes. During analysis, recordings were replayed and transcripts were re-read repeatedly to ensure the data supported the analysis.

\section{Research team and reflexivity}

The qualitative analysis was conducted by TC, KS, and PJ, none of whom were previously known to the research participants in any capacity, and had not been involved with running the mindfulness for psychosis groups at the CMHT. The research students (TC \& KS) were 
undertaking a masters-level degree in applied clinical psychology, and had previous work experience in mental health services. Both had some limited personal experience of experiential mindfulness practice, including using a mindfulness app. To enhance transparency, they both kept reflexive journals when conducting the interviews, to reflect on how their multiple identities, life experiences, and beliefs and assumptions may be impacting on their interpretation of the emerging data. They were trained and supervised by PJ, a Clinical Psychologist and Mindfulness teacher, whose area of clinical and research expertise was psychosis.

\section{Results}

\section{Participant characteristics}

Five people took part in the study. The sample comprised of 4 women and $1 \mathrm{man}$, all of whom had a diagnosis of a schizophrenia-Spectrum disorder (ICD-10 [45]; F20F29), with an average age of 45 years old (range 24-60). All had taken part in a mindfulness for psychosis group at the CMHT within the last 12 months. We asked each participant to self-report how much home-practice they had completed during their mindfulness group, and since finishing the groups to provide additional contextual data for their interviews (Table 3). All participants reported completing at least some formal home practice during their group, and 4/5 reported still practising at least once a week.

\section{Qualitative findings}

We entitled our thematic map the territory of home practice' as this encapsulated our exploration with the participants in 'mapping out' their experiences (Fig. 2). Our final model had three main themes; (1) Practice is difficult but important (central theme), (2) Tailoring home practice to fit, and (3) Help comes from both within and without. Central findings are summarised below.

1. Practice is difficult but important
Participants viewed home practice as important, and a key part of them benefitting from the mindfulness group in the longer term. However, participants also experienced conflict in knowing home practice would be helpful, but finding it hard to do for various reasons. A sub-theme related to 'creating the right conditions'. The 'right' conditions related to both the external 'weather pattern' (e.g. noise coming from the street or children at home being distracting), and the internal weather, such as the presence of physical pain, and difficult thoughts and emotions.

\section{if I'm trying to be mindful (.) sometimes (.) if I'm in a bad mood (.) it makes me a lot more aware of trou- bling thoughts (.) and you know (.) that I sometimes might not acknowledge (.) you know (5) so although I do still use mindfulness (.) you know (.) sometimes it's not always a peaceful experience (3) (P3)}

There were few direct references to psychotic symptoms specifically, although some participants did mention the presence of voices during practice, or thoughts about being unsafe.

\section{and (.) also (.) things like (.) if I heard a helicopter overhead (.) cause that's one of things (.) you know (.) I fear they were monitoring me (.) or something (P3)}

However, there was no special 'positioning' of psychotic experiences; for example, one participant said that they were just as likely to be put off from practising when their pain from a chronic health condition was bad, as they would from how their mental state was. One participant also reflected on how mindfulness practice was anathema to the 'cult of busyness', in that it could seem wasteful or indulgent to sit and deliberately cultivate 'non-doing'.

$\square$ Exactly (2) yeah because (.) you know (.) with mindfulness (.) the biggest block is that you can't see the effect (.) they're VERY subtle (2) so even after you finish mindfulness session (.) you're like (.) why did I just waste my time ((laughs)) (P4)

Table 3 Participant details on frequency of mindfulness practice

\begin{tabular}{llll}
\hline $\begin{array}{l}\text { Participant } \\
\text { number }\end{array}$ & $\begin{array}{l}\text { How long ago taken } \\
\text { part in mindfulness } \\
\text { group }\end{array}$ & $\begin{array}{l}\text { On an average week, any formal home-practice } \\
\text { done whilst taking part in mindfulness group } \\
\text { (self-report) }\end{array}$ & $\begin{array}{l}\text { On an average week, any formal home-practice } \\
\text { done since finishing the mindfulness group } \\
\text { (self-report) }\end{array}$ \\
\hline 1 & Less than three months & At least once a week & At least once a week \\
2 & Less than six months & At least every day & Never \\
3 & Less than 12 months & Several times a week & At least once a week \\
5 & Less than 12 months & Several times a week & Several times a week \\
5 & Less than one month & At least every day & At least every day \\
\hline
\end{tabular}




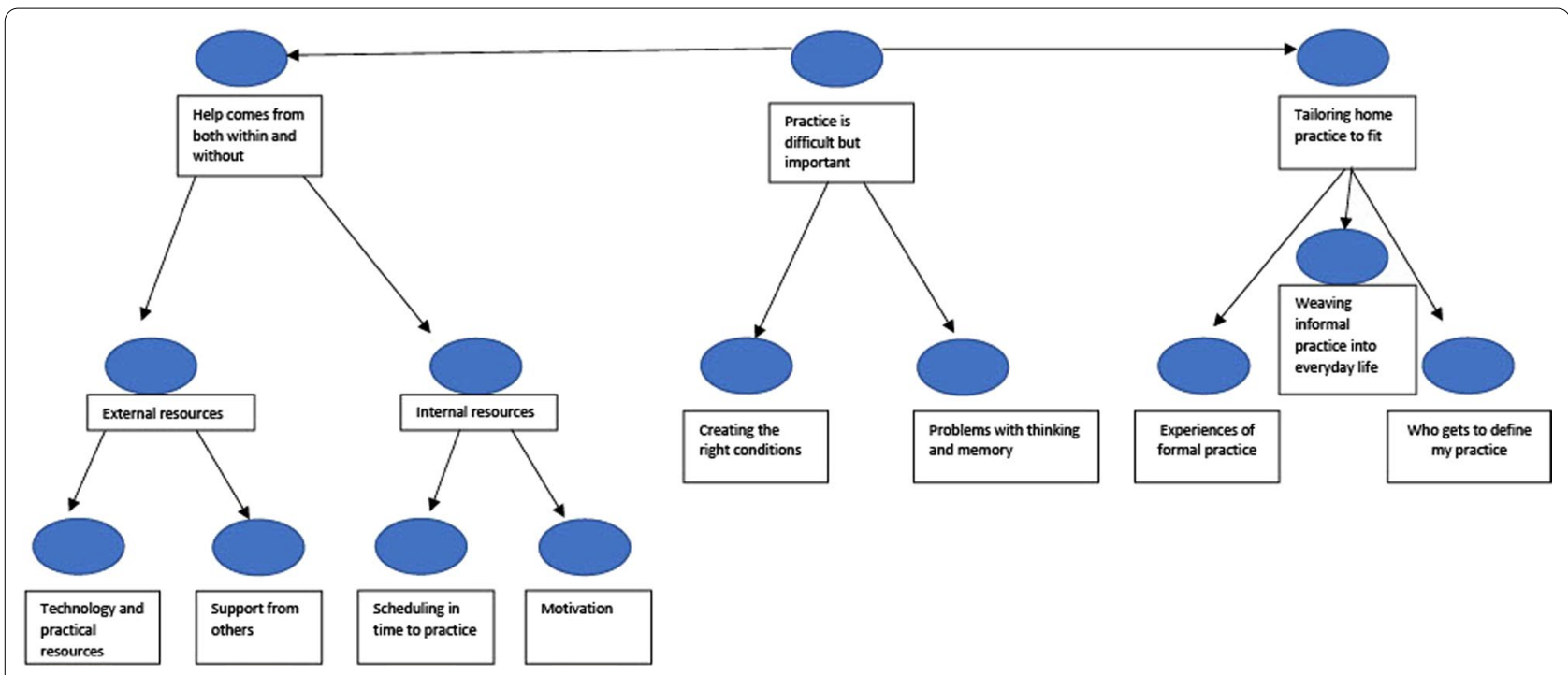

Fig. 2 Qualitative results thematic map: the territory of home practice

Problems with memory or thinking were mentioned by three out of five participants e.g. "cause I forget a lot (3) so maybe forgetfulness (.) always forgetting things" (P1). These difficulties were not ascribed to any particular cause, but were viewed as fairly long-standing difficulties, which participants were used to having to work around and adapt to.

\section{Tailoring home practice to fit}

An unexpected finding which arose in the analysis was that participants often challenged the conventional definition of 'formal' and 'informal' practice which we set out for them at the beginning of each interview script '(subtheme of 'who gets to define my practice'). For example, P1 described a 'soles of the feet' practice on the bus on her way home from a mindfulness group session, and how they viewed this as 'formal' rather than informal, given their intention to turn towards their experience in a mindful attitude. Participants also described using practises in a way which was helpful to them, even if they were aware this not necessarily the intended purpose. For example, falling asleep is a common experience in mindfulness practises (particularly when lying down, such as in the body scan). One participant described using this to their advantage, even though they were aware this not the intended purpose necessarily.

I- I-I I wouldn't say it's mindfulness (.) cause my intention (.) would be to- to- ur:::m (2) make me more relaxed (.) where I-I-I sleep better (.) it's notit's not like a (2) I don't do it intentionally (.) tourm- to- as a- (.) I don't do it as an (.) intentional

\section{practice (2) it's more of a (.) just a tool for me to go to sleep (P4)}

The sub-theme of 'weaving informal practice into everyday life' related to how people applied the mindfulness skills, and attitudinal qualities (e.g. curiosity, compassion) into everyday experiences and how beneficial they had found this. The descriptions of noticing the mundane and everyday were frequently very joyful and light-hearted as P2 describes here.

well I do the informal one (.) you know (.) I do- I dothese with my kids (2) and I tell them (.) $\square \mathrm{OH}$ (.) the sun is SHINING (2) the birds are singing (.) it's a beautiful day (.) make every second count (P2)

\section{Help comes from both within and without.}

Participants valued both internal resources e.g. their own motivation, and their own strategies for completing home practice, as well as external resources, such as use of CDs and apps, and support from others. At the heart of home practice, was the belief that it was helpful, and the motivation to try to overcome difficulties which had led them to try the group in the first place.

need to get better (2) because I really wanted to (.) get out of (.) depression (2) and it-it did help (3) (P2) Yeah (.) it's more for my brain (.) really (.) that's the best motivating thing (2) because I know it's benefitting my brain (.) it's like (.) when you're eating healthy food and you feel good about yourself (.) so when I do it (.) I'm like giving rest to my brain (2) so 


\section{that makes me feel good (P4)}

Support from others, including family members, and the mindfulness group therapists, were important in supporting people to maintain their practice. The opportunity to attend monthly follow-up sessions was particularly valued as it helped provide an anchor to the group which stopped it being forgotten.

YEAH (.) that one I- I- I'm thinking (.) the group here actually reminds us to keep doing mindfulness (2) because (.) you know why we-we-(.) my memory is not very good (.) and if I stopped it (.) I'll forget straight away (2) but when I come here (.) it reminds me (P5)

Support from other group members, both during the group, and in monthly follow-ups were particularly valued, with participants describing in very warm terms how they felt understood and inspired by others in the group with similar struggles.

$\square$ OF COU:::RSE that gives you more $\square$ wings to fly (2) you know (.) when you-when you notice (.) someone is pushing you to succeed (.) you know (.) someone looks (3) ur::m (.) cares about your wellness and everything (.) you know (.) it's wings for you to fly ((laughs)) (P2)

\section{Discussion}

This study aimed to review the current literature on home practice in mindfulness-based interventions for psychosis groups, and to investigate participants' perspectives on the barriers and facilitators to home practice. We found that although over a third of studies in our review recommended home practice as either an optional or core requirement of the group $(37 \% ; 16 / 43)$, only five studies reported any data on how much home practice people were doing. The findings from our qualitative study suggested that home practice was challenging but valued.

Our findings that home practice is rarely reported in mindfulness for psychosis studies was surprising given that many did mention home practice as part of the group protocol, and supporting materials such as CDs and handouts, were commonly provided. In addition to the five studies which reported data on home practice [18-22], one additional study stated that home practice monitoring was conducted by way of weekly record sheets, but this data was not reported in the paper [46]. Monitoring or recording of home practice was not explicitly mentioned in the remaining studies. This does not necessarily mean that no data on home practice was collected; only that none was reported in the paper. There may have been a range of ways in which home practice was reviewed and used clinically within the groups, for example by participants giving verbal reports when reviewing home practice in the group, without formal records being kept by participants or teachers.

Several factors may explain why homework was encouraged, and perhaps even discussed and recorded (but not reported) in these studies. Clinicians and researchers may believe that home practice is not likely to be associated with better treatment outcome in people with psychosis, hence there is no need to report data on it. However, this attitude would be surprising given previous meta-analyses including both clinical and non-clinical samples which suggest a clear link between increased homework completion and better therapeutic outcomes $[11,12]$. An alternative explanation could be that home practice is considered potentially valuable, but concerns remain about the burden on participants in being asked to complete homework diaries or similar in a formal way.

From the available data, it is currently unclear to what degree a review of home practice was a standard part of the group curriculum (whether or not they reported data in the journal paper). Where home practice was not reviewed or monitored within the groups, this could be due to therapists' concerns about potentially triggering shame or guilt in a vulnerable clinical population if they struggle to complete home practice, or to record it accurately. However, it is interesting to contrast this with the approach taken in Mindfulness based Cognitive Therapy (MBCT) for depression trials which have taken a more robust approach to recording homework e.g. [47]. Home practice is set and recorded each week, despite the fact that sensitivity to perceived failure and tendency towards self-criticism is commonly found in people with a history of depression $[48,49]$. In fact, working with self-critical thoughts triggered by a 'failure' experience around home practice can offer an opportunity to practice compassionate responding in a mindfulness class, if handled skilfully by the group therapist. Participants in one of the earliest published mindfulness-based interventions for psychosis studies rated Yalom's [50] therapeutic factor of 'universality' as one of the most important group factors which promoted a good therapeutic outcome [4]. Therefore, given how common struggles with home practice are, hearing that other group members are having similar challenges could be very normalising for people if home practice review is included in the weekly group curriculum.

The findings of the qualitative study in terms of barriers and facilitators to home practice are largely consistent with previous qualitative studies. We did not find any sense of special 'positioning' of psychotic symptoms, such as voices or paranoid thoughts, although 
some mention was made of these experiences in the interviews (e.g. the sound of a helicopter overhead triggering worries about being monitored). Participants mostly described 'everyday' barriers to home practice, such as children being at home, or noise coming from the street. This fits with previous qualitative studies in psychosis which mention noisy home environments, or external interruptions, as barriers to home practice $[18,35]$. Furthermore, our participants reflected on the role of the 'internal' environment, given how mindfulness involves turning towards what is present; therefore it is challenging to practice when this involves coming into contact with unwanted emotional states, although arguably this is when mindfulness skills can be honed most effectively. This also fits with the findings of the general community study in which people described a reluctance to practice when they felt bored or irritated because these are difficult emotions to sit with [13]. In terms of facilitators to practice, a belief that mindfulness was helpful, and a motivation to 'get better' helped people to at least try to practice at home, or when out and about. Practical resources such as the audio recordings provided, and also support from family, and from the mindfulness group were also valued.

These findings are consistent with the COM-B model [51], in which behavioural change is theorised to arise from people's capability, motivation and opportunity to successfully implement the change. In mindfulness for psychosis groups, participants are perhaps viewed as motivated to practice at home and are given the opportunity to do so (i.e. through setting homework practices and providing guided meditations on CDs/digital files). However, people with psychosis may not have hitherto been seen as capable of home practice, hence the reluctance to monitor or record home practice effectively. This may arise from benevolent paternalism [52], which although well-intentioned, may actually harm patients by limiting the effectiveness of therapies they receive by blocking access to certain components which are deemed 'risky', such as home practice.

With regards to clinical implications, Masheder et al. [53] further use the COM-B model as a framework for seven proposed factors that mindfulness teachers can use to help them support participants in completing home practice: (1) self-efficacy; (2) self-care; (3) beliefs about practice; (4) planning/commitment; (5) social support; (6) the relationship with the teacher and; (7) experiencing the rewards of practice. This framework can be a useful guide to ensure effective implementation of behavioural change through addressing each factor, such as encouraging participants to plan ahead to make time to practice, and framing practice as an act of self-care, rather than a chore. Our findings would suggest these factors should apply in mindfulness for psychosis groups, as in other mindfulness groups, and their effectiveness should be further explored in future studies.

In terms of strengths and limitations of the current study, we pre-specified and published our search strategy and review protocol in advance, and defined 'mindfulness-based interventions for psychosis' groups quite broadly for the sake of maximising the breadth of the systematic review. We did not search the grey literature however, or unpublished theses, so it is possible there were relevant studies outside the peer-reviewed literature which were not included in our review.

For the qualitative study, we purposively sampled people who had taken part in a mindfulness for psychosis group, but we were not able to specifically select people depending on whether they had or had not completed any home practice. Although we endeavoured to convey our interest and enthusiasm in speaking to people who had both done, and not done, any home practice, it is possible that people who had found home practice extremely difficult would not have felt comfortable volunteering to participate in the study. Further work would therefore need to be done in proactively seeking to recruit such participants in qualitative studies, to understand the experiences of people who do not do any home practice at all, and the reasons underlying this. We sampled people all from the same service (although not all from the same group cohort), which allowed us to explore experiences in one particular context in some depth, as is the aim of qualitative research, rather than to 'generalise' as in the positivist framework more commonly applied in quantitative research [54]. We also do not make any claims in relation to have achieved 'data saturation', as this is a inconsistently defined term in qualitative research $[55,56]$, and sample size may be better informed by 'information power' [57], which focuses on key dimensions such as study aim and sample specificity. Our study aim was relatively narrow, and the participants held highly specific characteristics in relation to the study aim (i.e. people who had recently completed a mindfulness for psychosis group), hence we regarded each 'case' as having high information power [58].

\section{Conclusions}

We highly recommend future mindfulness for psychosis group studies record and report home practice more thoroughly, so that the link between home practice and treatment outcome can be effectively evaluated, and treatment guidelines can be updated accordingly. 


\begin{abstract}
Abbreviations
CDs: Compact discs; CMHT: Community Mental Health Team; COM-B model: Capability, opportunity, motivation, and behaviour model; ICD-10: International Classification of Diseases-10th edition; IPA: Interpretative phenomenological analysis; MBSR: Mindfulness-Based Stress Reduction; MBCT: Mindfulness-Based Cognitive Therapy; MMAT: Mixed Methods Appraisal Tool; NHS: National Health Service; PRISMA: Preferred Reporting Items for Systematic Reviews and Meta-Analyses; RCTs: Randomised controlled trials; TAU: Treatment as Usual; UK: United Kingdom.
\end{abstract}

\section{Supplementary Information}

The online version contains supplementary material available at https://doi. org/10.1186/s40359-021-00694-4.

Additional file 1. 1. Search Terms. 2. Figure S3. PRISMA diagram for secondary searches (qualitative). 3. Semi-structured interview topic guide. 4. Key to Jeffersonian Transcription Notation.

\section{Acknowledgements}

Not applicable.

\section{Authors' contributions}

PJ designed the study, supervised data collection and data analysis, and wrote the initial draft of the manuscript. TC, KS, and CM collected the data, and conducted the data analysis. All authors contributed to data interpretation. All authors contributed to reviewing and revising the manuscript. All authors approved the manuscript for submission. All authors read and approved the final manuscript.

\section{Funding}

The authors received no financial support for the research, authorship, and/or publication of this article.

\section{Availability of data and materials}

The datasets used and/or analysed during the current study are available from the corresponding author on reasonable request.

\section{Declarations}

\section{Ethics approval and consent to participate}

The study was reviewed and given a favourable opinion by the LondonSurrey Borders Research Ethics Committee (REC reference: 19/LO/0843; date 10/05/2019) and approved by the Health Research Authority (IRAS number: 261396; date 10/06/2019). All participants gave written consent.

\section{Consent for publication}

Not applicable.

\section{Competing interests}

The authors declare no potential conflicts of interest with respect to the research, authorship, and/or publication of this article.

\section{Author details}

${ }^{1}$ Department of Psychology, University of Bath, Bath BA2 7AY, UK. ${ }^{2}$ South London and Maudsley NHS Foundation Trust, London, UK.

Received: 2 November 2020 Accepted: 25 November 2021

Published online: 12 January 2022

\section{References}

1. Jansen JE, Gleeson J, Bendall S, Rice S, Alvarez-Jimenez M. Acceptanceand mindfulness-based interventions for persons with psychosis: a systematic review and meta-analysis. Schizophr Res. 2020;215:25-37.
2. Louise S, Fitzpatrick M, Strauss C, Rossell SL, Thomas N. Mindfulness- and acceptance-based interventions for psychosis: our current understanding and a meta-analysis. Schizophr Res. 2018;192:57-63.

3. Chadwick P. Mindfulness for psychosis. Br J Psychiatry. 2014;204:333.

4. Chadwick P, Taylor KN, Abba N. Mindfulness groups for people with psychosis. Behav Cogn Psychother. 2005;33(3):351-9.

5. de Boer JN, Corona Hernández H, Gerritse F, Brederoo SG, Wijnen FNK, Sommer IE. Negative content in auditory verbal hallucinations: a natural language processing approach. Cogn Neuropsychiatry. 2021. https:// doi.org/10.1080/13546805.2021.1941831.

6. Sheffield JM, Karcher NR, Barch DM. Cognitive deficits in psychotic disorders: a lifespan perspective. Neuropsychol Rev. 2018;28(4):509-33.

7. Kabat-Zinn J. Full catastrophe living: using the wisdom of your body and mind to face stress, pain, and illness. 15th anniversary ed. New York: Delta Trade Paperback/Bantam Dell; US; 2005.

8. Segal ZV, Williams JMG, Teasdale JD. Mindfulness-Based Cognitive Therapy for depression. 2nd ed. New York: Guilford Press; 2013.

9. Lacaille J, Sadikaj G, Nishioka M, Carrière K, Flanders J, Knäuper B. Daily mindful responding mediates the effect of meditation practice on stress and mood: the role of practice duration and adherence. J Clin Psychol. 2018;74(1):109-22.

10. Crane C, Crane RS, Eames C, Fennell MJV, Silverton S, Williams JMG, et al. The effects of amount of home meditation practice in Mindfulness Based Cognitive Therapy on hazard of relapse to depression in the staying well after depression trial. Behav Res Ther. 2014;63:17-24.

11. Parsons CE, Crane C, Parsons LJ, Fjorback LO, Kuyken W. Home practice in Mindfulness-Based Cognitive Therapy and Mindfulness-Based Stress Reduction: a systematic review and meta-analysis of participants' mindfulness practice and its association with outcomes. Behav Res Ther. 2017;95:29-41.

12. Lloyd A, White R, Eames C, Crane R. The utility of home-practice in mindfulness-based group interventions: a systematic review. Mindfulness. 2018;9(3):673-92.

13. Birtwell K, Williams K, van Marwijk H, Armitage CJ, Sheffield D. An exploration of formal and informal mindfulness practice and associations with wellbeing. Mindfulness. 2019;10(1):89-99.

14. Cairns V, Murray C. How do the features of Mindfulness-Based Cognitive Therapy contribute to positive therapeutic change? A meta-synthesis of qualitative studies. Behav Cogn Psychother. 2015;43(3):342-59.

15. Wyatt $C$, Harper B, Weatherhead S. The experience of group mindfulness-based interventions for individuals with mental health difficulties: a meta-synthesis. Psychother Res. 2014;24(2):214-28.

16. Pace R, Pluye P, Bartlett G, Macaulay AC, Salsberg J, Jagosh J, et al. Testing the reliability and efficiency of the pilot Mixed Methods Appraisal Tool (MMAT) for systematic mixed studies review. Int J Nurs Stud. 2012:49(1):47-53.

17. Higgins JPT, Altman DG, Goetzsche PC, Juni P, Moher D, Oxman AD, et al. The cochrane collaboration's tool for assessing risk of bias in randomised trials. BMJ. 2011;343:d5928.

18. Brown LF, Davis LW, LaRocco VA, Strasburger A. Participant perspectives on mindfulness meditation training for anxiety in schizophrenia. Am J Psychiatr Rehabil. 2010;13(3):224-42.

19. Davis LW, Strasburger AM, Brown LF. Mindfulness: an intervention for anxiety in schizophrenia. J Psychosoc Nurs Ment Health Serv. 2007:45(11):23-9.

20. Davis LW, Lysaker PH, Kristeller JL, Salyers MP, Kovach AC, Woller S. Effect of mindfulness on vocational rehabilitation outcomes in stable phase schizophrenia. Psychol Serv. 2015;12(3):303-12.

21. Johnson DP, Penn DL, Fredrickson BL, Kring AM, Meyer PS, Catalino LI, et al. A pilot study of loving-kindness meditation for the negative symptoms of schizophrenia. Schizophr Res. 2011;129(2-3):137-40.

22. Lam AHY, Leung SF, Lin JJ, Chien WT. The effectiveness of a mindfulness-based psychoeducation programme for emotional regulation in individuals with schizophrenia spectrum disorders: a pilot randomised controlled trial. Neuropsychiatr Dis Treat. 2020;16:729-47.

23. Jacobsen P, Morris E, Johns L, Hodkinson K. Mindfulness groups for psychosis; key issues for implementation on an inpatient unit. Behav Cogn Psychother. 2011;39(3):349-53.

24. Moorhead S. Report of a feasibility study of a Mindfulness group for clients, carers and staff of an early intervention in psychosis service. Cogn Behav Ther. 2012;5(4):93-101. 
25. Samson C, Mallindine C. The feasibility and effectiveness of running mindfulness groups in an early intervention in psychosis service. Cogn Behav Ther. 2014;7:E9. https://doi.org/10.1017/S1754470X14000087.

26. Spidel A, Lecomte T, Kealy D, Daigneault I. Acceptance and commitment therapy for psychosis and trauma: improvement in psychiatric symptoms, emotion regulation, and treatment compliance following a brief group intervention. Psychol Psychother Theory Res Pract. 2018;91(2):248-61.

27. Tong AC, Lin JJ, Cheung VY, Lau NK, Chang WC, Chan SK, et al. A low-intensity mindfulness-based intervention for mood symptoms in people with early psychosis: development and pilot evaluation. Clin Psychol Psychother. 2016;23(6):550-60.

28. Böge K, Karadza A, Fuchs LM, Ehlen F, Ta TMT, Thomas N, et al. Mindfulness-based interventions for in-patients with schizophrenia spectrum disorders - a qualitative approach. Front Psychiatry. 2020;11:600. https://doi.org/10.3389/fpsyt.2020.00600.

29. Thompson A, Senders A, Seibel C, Usher C, Borgatti A, Bodden K, et al. Qualitative analysis of the Meals, Mindfulness, \& Moving Forward (M(3) ) lifestyle programme: cultivating a "safe space" to start on a "new path" for youth with early episode psychosis. Early Interv Psychiatry. 2021;15(1):87-95.

30. York M. A qualitative study into the experience of individuals involved in a mindfulness group within an acute inpatient mental health unit. J Psychiatr Ment Health Nurs. 2007;14(6):603-8.

31. Ashcroft K, Barrow F, Lee R, MacKinnon K. Mindfulness groups for early psychosis: a qualitative study. Psychol Psychother Theory Res Pract. 2012:85(3):327-34.

32. Dennick L, Fox AP, Walter-Brice A. Mindfulness groups for people experiencing distressing psychosis: an interpretative phenomenological analysis. Ment Health Rev J. 2013;18:32-43.

33. May K, Strauss C, Coyle A, Hayward M. Person-based cognitive therapy groups for distressing voices: a thematic analysis of participant experiences of the therapy. Psychosis. 2014;6(1):16-26.

34. Abba N, Chadwick P, Stevenson C. Responding mindfully to distressing psychosis: a grounded theory analysis. Psychother Res. 2008;18(1):77-87.

35. McHale C, Hayward M, Jones FW. Building a grounded theory of engagement in mindfulness-based group therapy for distressing voices. Qual Health Res. 2018;28(14):2169-82.

36. Ting KT, Tam W, Jacobsen P. Mindfulness for psychosis groups; description and preliminary evaluation of a novel routine care pathway in Hong Kong. Int J Ment Health Syst. 2020;14(1):81.

37. Millar A, Tip L, Lennon R, Macinnes M, Michalska B, Lawrie SM, et al. The introduction of mindfulness groups to a psychiatric rehabilitation in-patient setting: a feasibility study. BMC Psychiatry. 2020;20(1):322.

38. Khoury B, Lecomte T, Comtois G, Nicole L. Third-wave strategies for emotion regulation in early psychosis: a pilot study. Early Interv Psychiatry. 2015;9(1):76-83.

39. Chadwick P. Relationship to internal experience: mindfulness practice. person-based cognitive therapy for distressing psychosis. Chichester: Wiley; 2006. p. 78-97.

40. Jacobsen P, Richardson M, Harding E, Chadwick P. Mindfulness for psychosis groups; within-session effects on stress and symptomrelated distress in routine community care. Behav Cogn Psychother. 2019:47(4):421-30.

41. Palinkas LA, Horwitz SM, Green CA, Wisdom JP, Duan N, Hoagwood K. Purposeful sampling for qualitative data collection and analysis in mixed method implementation research. Adm Policy Ment Health. 2015;42(5):533-44.

42. Jefferson G. Transcription notation. In: Atkinson J, Heritage J, editors. Structures of social interaction. New York: Cambridge University Press; 1984

43. Braun V, Clarke V. Using thematic analysis in psychology. Qual Res Psychol. 2006;3(2):77-101.

44. Clarke V, Braun V. Using thematic analysis in counselling and psychotherapy research: a critical reflection. Couns Psychother Res. 2018;18(2):107-10.

45. World Health Organization. International statistical classification of diseases and related health problems. 10th ed. Geneva: World Health Organization; 2010
46. Sheng J-L, Yan Y, Yang X-H, Yuan T-F, Cui D-H. The effects of Mindfulness Meditation on hallucination and delusion in severe schizophrenia patients with more than 20 years' medical history. CNS Neurosci Ther. 2019;25(1):147-50.

47. Williams JMG, Crane C, Barnhofer T, Brennan K, Duggan DS, Fennell MJV, et al. Mindfulness-Based Cognitive Therapy for preventing relapse in recurrent depression: a randomized dismantling trial. J Consult Clin Psychol. 2014;82(2):275-86.

48. MacBeth A, Gumley A. Exploring compassion: a meta-analysis of the association between self-compassion and psychopathology. Clin Psychol Rev. 2012;32(6):545-52.

49. Ehret AM, Joormann J, Berking M. Examining risk and resilience factors for depression: the role of self-criticism and self-compassion. Cogn Emot. 2015;29(8):1496-504.

50. Yalom ID, Leszcz M. The theory and practice of group psychotherapy. 5th ed. New York: Basic Books; 2005.

51. Michie S, van Stralen MM, West R. The behaviour change wheel: a new method for characterising and designing behaviour change interventions. Implement Sci. 2011;6(1):42.

52. Clarke S. A definition of paternalism. Crit Rev Int Soc Polit Philos. 2002;5(1):81-91.

53. Masheder J, Fjorback L, Parsons CE. "I am getting something out of this, so I am going to stick with it": supporting participants' home practice in Mindfulness-Based Programmes. BMC Psychol. 2020;8(1):91.

54. Carminati L. Generalizability in qualitative research: a tale of two traditions. Qual Health Res. 2018;28(13):2094-101.

55. Braun V, Clarke V. To saturate or not to saturate? Questioning data saturation as a useful concept for thematic analysis and sample-size rationales. Qual Res Sport Exerc Health. 2021;13(2):201-16.

56. O'Reilly M, Parker N. 'Unsatisfactory saturation': a critical exploration of the notion of saturated sample sizes in qualitative research. Qual Res. 2013;13(2):190-7.

57. Malterud K, Siersma VD, Guassora AD. Sample size in qualitative interview studies: guided by information power. Qual Health Res. 2016:26(13):1753-60.

58. Young DS, Casey EA. An examination of the sufficiency of small qualitative samples. Soc Work Res. 2018;43(1):53-8.

59. Böge K, Hahne I, Bergmann N, Wingenfeld K, Zierhut M, Thomas N, et al. Mindfulness-based group therapy for in-patients with schizophrenia spectrum disorders - feasibility, acceptability, and preliminary outcomes of a rater-blinded randomized controlled trial. Schizophr Res. 2021:228:134-44

60. Çetin N, Aylaz R. The effect of mindfulness-based psychoeducation on insight and medication adherence of schizophrenia patients. Arch Psychiatr Nurs. 2018;32(5):737-44.

61. Chadwick P, Hughes S, Russell D, Russell I, Dagnan D. Mindfulness groups for distressing voices and paranoia: a replication and randomized feasibility trial. Behav Cogn Psychother. 2009;37(4):403-12.

62. Chadwick P, Strauss C, Jones A-M, Kingdon D, Ellett L, Dannahy L, et al Group mindfulness-based intervention for distressing voices: a pragmatic randomised controlled trial. Schizophr Res. 2016;175(1-3):168-73.

63. Chien WT, Lee IY. The mindfulness-based psychoeducation program for Chinese patients with schizophrenia. Psychiatr Serv. 2013:64(4):376-9.

64. Chien WT, Thompson DR. Effects of a mindfulness-based psychoeducation programme for Chinese patients with schizophrenia: 2-year followup. Br J Psychiatry. 2014;205(1):52-9.

65. Wang LQ, Chien WT, Yip LK, Karatzias T. A randomized controlled trial of a mindfulness-based intervention program for people with schizophrenia: 6-month follow-up. Neuropsychiatr Dis Treat. 2016;12:3097-110.

66. Chien WT, Bressington D, Yip A, Karatzias T. An international multi-site, randomized controlled trial of a mindfulness-based psychoeducation group programme for people with schizophrenia. Psychol Med. 2017:47(12):2081-96.

67. Chien WT, Cheng HY, McMaster TW, Yip ALK, Wong JCL. Effectiveness of a mindfulness-based psychoeducation group programme for early-stage schizophrenia: an 18-month randomised controlled trial. Schizophr Res. 2019;212:140-9.

68. Chien WT, Chow KM, Chong YY, Bressington D, Choi KC, Chan CWH. The role of five facets of mindfulness in a mindfulness-based psychoeducation intervention for people with recent-onset psychosis on mental 
and psychosocial health outcomes. Front Psychiatry. 2020. https://doi. org/10.3389/fpsyt.2020.00177.

69. Dannahy L, Hayward M, Strauss C, Turton W, Harding E, Chadwick P. Group person-based cognitive therapy for distressing voices: pilot data from nine groups. J Behav Ther Exp Psychiatry. 2011;42(1):111-6.

70. Ellett L, Tarant E, Kouimtsidis C, Kingston J, Vivarelli L, Mendis J, et al. Group mindfulness-based therapy for persecutory delusions: a pilot randomised controlled trial. Schizophr Res. 2020;222:534-6.

71. Hickey T, Nelson B, Enticott J, Meadows G. The MAC-P program: a pilot study of a mindfulness and compassion program for youth with psychotic experiences. Early Interv Psychiatry. 2021;15(5):1326-34.

72. Hickey T, Pen Name E, Nelson B, Meadows G. Mindfulness and compassion for youth with psychotic symptoms: a description of a group program and a consumer's experience. Psychosis. 2019;11(4):342-9.

73. Jones AM, Strauss C, Hayward M. A service evaluation of a group mindfulness-based intervention for distressing voices: how do findings from a randomized controlled trial compare with routine clinical practice? Behav Cogn Psychother. 2021;49(1):76-90.

74. Langer Al, Cangas AJ, Salcedo E, Fuentes B. Applying mindfulness therapy in a group of psychotic individuals: a controlled study. Behav Cogn Psychother. 2012;40(1):105-9.

75. Langer Ál, Schmidt C, Vergara R, Mayol-Troncoso R, Lecaros J, Krogh $E$, et al. Examining the effect of a mindfulness based program for the improvement of cognitive function in an early stage of schizophrenia. A random controlled trial. Schizophr Res. 2020;223:370-2.

76. Lee $\mathrm{KH}$. A randomized controlled trial of mindfulness in patients with schizophrenia. Psychiatry Res. 2019;275:137-42.

77. López-Navarro E, Del Canto C, Belber M, Mayol A, Fernandez-Alonso $\mathrm{O}$, Lluis J, et al. Mindfulness improves psychological quality of life in community-based patients with severe mental health problems: a pilot randomized clinical trial. Schizophr Res. 2015;168(1-2):530-6.

78. López-Navarro E, Del Canto C, Mayol A, Fernández-Alonso O, Reig J, Munar E. Does mindfulness improve inhibitory control in psychotic disorders? A randomized controlled clinical trial. Int J Clin Health Psychol. 2020;20(3):192-9.

79. López-Navarro E, Al-Halabí S. Effects of mindfulness on psychotic symptoms: insights from a randomized clinical trial. Psychosis. 2021. https:// doi.org/10.1080/17522439.2021.1889649.

80. MacDougall AG, Price E, Vandermeer MRJ, Lloyd C, Bird R, Sethi R, et al. Youth-focused group mindfulness-based intervention in individuals with early psychosis: a randomized pilot feasibility study. Early Interv Psychiatry. 2019:13(4):993-8

81. Martins MJ, Castilho P, Santos V, Gumley A. Schizophrenia: an exploration of an acceptance, mindfulness, and compassion-based group intervention. Aust Psychol. 2017;52(6):514-23.

82. Mediavilla R, Muñoz-Sanjose A, Rodriguez-Vega B, Bayon C, Lahera G, Palao A, et al. Mindfulness-based social cognition training (SocialMind) for people with psychosis: a feasibility trial. Front Psychiatry. 2019. https://doi.org/10.3389/fpsyt.2019.00299.

83. Özdemir AA, Kavak Budak F. The effects of mindfulness-based stress reduction training on hope, psychological well-being, and functional recovery in patients with schizophrenia. Clin Nurs Res. 2021. https://doi. org/10.1177/10547738211039069.

84. Randal C, Bucci S, Morera T, Barrett M, Pratt D. Mindfulness-Based Cognitive Therapy for psychosis: measuring psychological change using repertory grids. Clin Psychol Psychother. 2016;23(6):496-508.

85. Ryan A, Crehan E, Khondoker M, Fell M, Curtin R, Johns LC. An emotional regulation approach to psychosis recovery: the Living Through Psychosis group programme. J Behav Ther Exp Psychiatry. 2021:72:101651

86. Shen $H$, Zhang $L, L i Y$, Zheng D, Du L, Xu F, et al. Mindfulness-based intervention improves residual negative symptoms and cognitive impairment in schizophrenia: a randomized controlled follow-up study. Psychol Med. 2021. https://doi.org/10.1017/S0033291721002944.

87. Tang Q, Yang S, Liu C, Li L, Chen X, Wu F, et al. Effects of MindfulnessBased Cognitive Therapy on stigma in female patients with schizophrenia. Front Psychiatry. 2021;12:694575.

88. Usher C, Thompson A, Griebeler M, Senders A, Seibel C, Ly R, et al. Meals, mindfulness, \& moving forward: a feasibility study to a multimodal lifestyle approach in early psychosis. Early Interv Psychiatry. 2019:13(1):147-50.
89. van der Valk R, van de Waerdt S, Meijer CJ, van den Hout I, de Haan L. Feasibility of mindfulness-based therapy in patients recovering from a first psychotic episode: a pilot study. Early Interv Psychiatry. 2013;7(1):64-70.

90. Yulina Astuti HW, Agustin M, Sari SP, Wijayanti DY, Sarjana W, Locsin RC. Effects of mindfulness on stimulating hope and recovery among people with schizophrenia. Nurse Media J Nurs. 2020;10(2):119-29.

91. Beck AT, Baruch E, Balter JM, Steer RA, Warman DM. A new instrument for measuring insight: the Beck Cognitive Insight Scale. Schizophr Res. 2004;68(2-3):319-29.

92. Overall JE, Gorham DR. The brief psychiatric rating scale. Psychol Rep. 1962:10:799-812.

93. Lukoff D, Nuechterlein K, Ventura J. Manual for the expanded brief psychiatric rating scale. Schizophr Bull. 1986;12:594-602.

94. Garnefski N, Kraaij V. Cognitive emotion regulation questionnairedevelopment of a short 18-item version (CERQ-short). Personal Individ Differ. 2006;41(6):1045-53.

95. Evans C, Mellor-Clark J, Margison F, Barkham M, Audin K, Connell J, et al. CORE: clinical outcomes in routine evaluation. J Ment Health. 2000:9(3):247-55.

96. Lovibond PF, Lovibond SH. Manual for the depression anxiety stress scales. Sydney: Psychology Foundation; 1995.

97. Gratz KL, Roemer L. Multidimensional assessment of emotion regulation and dysregulation: development, factor structure, and initial validation of the difficulties in emotion regulation scale. J Psychopathol Behav Assess. 2004;26(1):41-54.

98. Herth K. Abbreviated instrument to measure hope: development and psychometric evaluation. J Adv Nurs. 1992;17(10):1251-9.

99. Link BG, Yang LH, Phelan JC, Collins PY. Measuring mental illness stigma. Schizophr Bull. 2004;30(3):511-41.

100. Kay SR, Fiszbein A, Opler LA. The positive and negative syndrome scale (PANSS) for schizophrenia. Schizophr Bull. 1987;13(2):261-76.

101. Derogatis LR, Lipman RS, Covi L. SCL-90: an outpatient psychiatric rating scale. Psychopharmacol Bull. 1973;9(1):13-28.

102. Golden CJ. Stroop color and word test: a manual for clinical and experimental uses. Chicago: Stoelting Co.; 1978.

103. Choe K. Development and preliminary testing of the Schizophrenia Hope Scale, a brief scale to measure hope in people with schizophrenia. Int J Nurs Stud. 2014;51(6):927-33.

104. Harper A, Power M, Orley J, Herrman H, Schofield H, Murphy B, et al. Development of the World Health Organization WHOQOL-BREF quality of life assessment. Psychol Med. 1998;28(3):551-8.

\section{Publisher's Note}

Springer Nature remains neutral with regard to jurisdictional claims in published maps and institutional affiliations.

$$
\begin{aligned}
& \text { Ready to submit your research? Choose BMC and benefit from: } \\
& \text { - fast, convenient online submission } \\
& \text { - thorough peer review by experienced researchers in your field } \\
& \text { - rapid publication on acceptance } \\
& \text { - support for research data, including large and complex data types } \\
& \text { - gold Open Access which fosters wider collaboration and increased citations }
\end{aligned}
$$$$
\text { - maximum visibility for your research: over 100M website views per year }
$$

\section{At $\mathrm{BMC}$, research is always in progress.}

Learn more biomedcentral.com/submissions 